\title{
INFLUÊNCIA DA REMEDIAÇÃO ELETROCINÉTICA NO AUMENTO DO CICLO DE VIDA DE CATALISADORES DESATIVADOS POR PROCESSO FCC
}

\author{
L.S. SANCHES ${ }^{1}$, R. B. G. VALT ${ }^{1}$, M. J. S. PONTE ${ }^{1}$, K. C. SANTOS ${ }^{2}$ E A. BROSKA ${ }^{2}$
}

1-Universidade Federal do Paraná- Departamento de Engenharia Mecânica

2- Universidade Federal do Paraná- Departamento de Engenharia Química

Email para contato:luschmidlinsanches@gmail.com

\begin{abstract}
RESUMO: O resíduo que provém do processo de craqueamento catalítico de petróleo em leito fluidizado (FCC) é composto em sua íntegra pelo catalisador desativado que foi utilizado neste processo. Para diminuir a periculosidade do resíduo e aumentar seu ciclo de vida, uma das maneiras é remover o Ni e V adsorvidos no catalisador através da aplicação da técnica de remediação eletrocinética. $\mathrm{O}$ estudo da readsorção de Ni no catalisador remediado tem o intuito de indicar o quanto este material ainda pode ser reaproveitado. Para analisar o perfil de adsorção de $\mathrm{Ni}$ no catalisador remediado com citrato de sódio $1,0 \mathrm{~mol} / \mathrm{l}$ e $11 \mathrm{~V}$ de campo elétrico, foram feitos os ensaios de adsorção em banho finito. Os resultados obtidos mostram que o Catalisador Novo apresentou uma porcentagem de adsorção de $\mathrm{Ni}$ de $68,82 \%$ e o Catalisador Remediado $42,87 \%$, enquanto o Catalisador Desativado 3,86\%. Em relação ao catalisador desativado, o catalisador remediado apresentou uma capacidade 11 vezes maior de adsorção de Ni.
\end{abstract}

\section{INTRODUÇÃO}

A cada dia, são utilizadas aproximadamente 1400 toneladas de catalisadores de craqueamento fluidizado de petróleo em 350 unidades de FCC no mundo inteiro, para o tratamento de óleo cada vez mais pesado, gerando grande quantidade de resíduo sólido contaminado com metais pesados e coque. No Brasil esta quantidade chega a 120 toneladas/mês por refinaria (COSTA, 2009), considerando as 16 refinarias existentes no país (PETROBRAS, 2005).

Este material é classificado como Classe I (resíduos perigosos), justificando, portanto, a pesquisa em novas tecnologias que possibilitem a diminuição da quantidade de resíduos produzidos, de modo a evitar que se transformem em fonte de contaminação ambiental e humana. Neste sentido, o catalisador desativado tem sido incorporado ao concreto em substituição ao cimento e também empregado como material pozolânico em argamassas. Uma alternativa para minimizar o problema seria o aumento do ciclo de vida destes catalisadores, e neste sentido o tratamento com remediação eletrocinética tem sido inédito e demonstrado bons resultados. Pois o material após remediação não sofre mudanças em suas estruturas químicas, e pode ser reempregado tanto na indústria do petróleo (VALT, 2012), como material adsorvente de outros metais em meios 
aquosos contaminados. Isso depende exclusivamente do eletrólito utilizado durante o processo de remediação.

Uma vez que, os catalisadores usados nestes processos aceleram as reações químicas, de modo a gerar novas frações de produto. Após alguns ciclos de uso e regeneração, os metais presentes na corrente de hidrocarboneto, principalmente níquel e vanádio, se acumulam na superfície do catalisador e causam sua desativação irreversível por formação de coque. A Remediação Eletrocinética, também chamada de descontaminação eletrocinética, pode ser usada para extrair estes metais da superfície do catalisador e assim regenerar o mesmo. (ACAR, 1995 apud EPA, 1997). Esta técnica baseia-se na aplicação de uma corrente direta de baixa intensidade ou de uma diferença de potencial mediante a introdução de placas de eletrodos em um reator eletrocinético. Os contaminantes são mobilizados na forma de espécies carregadas ou partículas. (BAPTISTA, 2005 e RAJESHWAR et al., 1994)

Neste trabalho, no entanto, o intuito é de mostrar a capacidade adsortiva do catalisador em relação ao $\mathrm{Ni}$, após sua remediação (regeneração), com intenção de aumentar seu ciclo de vida e diminuir seu impacto sobre o meio ambiente. Uma vez que o processo de remediação permite a formação de um ciclo de regeneração tanto do catalisador, quanto do resíduo gerado, que é constituído pelos metais removidos do catalisador e o eletrólito suporte. Este resíduo pode após remediação ser direcionado a um segundo reator, de leito particulado (PONTE,1998), onde é feita a recuperação dos metais de forma seletiva por eletrodeposição, uma vez que o citrato de sódio, por ser complexante de $\mathrm{V}$ e Ni, favorece tanto o processo de remoção (reator eletrocinético-RE) como de eletrodeposição (reator de leito fluidizado-RLF) (SANCHES et al. , 2003).

\section{MATERIAIS E MÉTODOS}

O catalisador desativado utilizado foi uma zeólita tipo Y, obtido da Refinaria Presidente Getúlio Vargas - PETROBRAS/REPAR. A remediação eletrocinética foi feita em diferentes condições, sendo o eletrólito suporte citrato de sódio , catodo de chumbo e anodo Ti/Ru-Ir.

Foram realizados ensaios cinéticos em banho finito a temperatura ambiente, aproximadamente $20^{\circ} \mathrm{C}$ e rotação de aproximadamente $300 \mathrm{rpm}$, utilizando concentrações iniciais de níquel de 50,100 e $150 \mathrm{mg} / \mathrm{L} \mathrm{em} \mathrm{pH} 6$ e tempo de 30 minutos. A solução contendo o adsorbato foi preparada com sulfato de níquel, $\mathrm{NiSO}_{4} \cdot 6 \mathrm{H}_{2} \mathrm{O}$.Os ensaios foram realizados em béckers de $250 \mathrm{~mL}$ de plásticos, com $2 \mathrm{~g}$ de catalisador remediado e $100 \mathrm{~mL}$ de solução de níquel e agitação de aproximadamente $300 \mathrm{rpm}$. O pH 6 da solução foi mantido constante. Após passagem pelo banho finito, as amostras foram filtradas e prepararam-se alíquotas da solução para que fosse possível determinar a concentração de equilíbrio através da Espectroscopia de Absorção Atômica.

Para verificar a interferência da área superficial foram realizados ensaios por sorção do gás nitrogênio (Método BET). As medidas de área superficial foram efetuadas em equipamento marca QUANTACHROME modelo NOVA 1200, sendo estas interpretadas utilizando o software Autosorb for Windows - Version 1.24. Frações 
(aprox. 1 a 3 gramas) de cada amostra foram preparadas, primeiramente em secagem em estufa na temperatura de $110{ }^{\circ} \mathrm{C}$ sob vácuo e posteriormente em sistema apropriado do equipamento, sob vácuo, na temperatura de $150{ }^{\circ} \mathrm{C}$ por 3 horas, sendo então analisadas pelo método B.E.T.

Com o objetivo de comparar os resultados, foram realizados ensaios com um catalisador novo e com um catalisador de equilíbrio (desativado).

\section{RESULTADOS}

\subsection{Remediação eletrocinética}

Com base nos resultados obtidos da remediação eletrocinética, TABELA 1, e levando-se em conta as concentrações de níquel e vanádio removidas do catalisador, que foram determinadas por Fluorescência de Raios-X no catalisador após remediação, o experimento 4 foi o que apresentou melhor resultado. Logo, nas condições estudadas, a concentração de 0,5 mol. $\mathrm{L}^{-1}$ de citrato de sódio no eletrólito suporte e aplicação de tensão de $11 \mathrm{~V}$ apresentam a maior quantidade em termos quantitativos da retirada de níquel e vanádio do catalisador . Foram feitos ensaios de TG, antes e após remediação e constatou-se que não houve mudanças na estrutura do catalisador.

Tabela 1 - Concentrações de níquel no eletrólito ao final de 8horas de remediação eletrocinética em diferentes condições experimentais de remediação.

\begin{tabular}{|c|c|c|c|c|}
\hline & $\begin{array}{c}\text { Concentração } \\
\text { do eletrólito } \\
\left(\text { mol. }^{-1}\right)\end{array}$ & $\begin{array}{c}\text { Tensão da } \\
\text { Fonte } \\
(\mathrm{V})\end{array}$ & $\begin{array}{c}\text { \% de Ni } \\
\text { removida }\end{array}$ & $\begin{array}{c}\text { \% de V } \\
\text { removida }\end{array}$ \\
\hline 1 & 0,5 & 5 & 24,0 & 21,6 \\
\hline 2 & 1,0 & 5 & 16,4 & 16,3 \\
\hline 3 & 1,0 & 11 & 20,8 & 27,4 \\
\hline 4 & 0,5 & 11 & 25,4 & 22,1 \\
\hline 5 & 0,75 & 8 & 1,6 & 18,5 \\
\hline
\end{tabular}

\section{2. Área específica pelo método B.E.T.}

A análise dos catalisadores através do método B.E.T mostrou que a área superficial do catalisador novo é $1,99 \times 10^{2} \mathrm{~m}^{2} / \mathrm{g}$, enquanto a área superficial do catalisador desativado é $0,95 \times 10^{2} \mathrm{~m}^{2} / \mathrm{g}$ e a área do catalisador remediado é $1,92 \times 10^{2}$ $\mathrm{m}^{2} / \mathrm{g}$, nas condições do experimento 4. Tais valores mostram que a remediação eletrocinética recupera parcialmente a área superficial do catalisador, sendo que o valor fica próximo ao observado no catalisador novo, o que indica um favorecimento no processo de readsorção de Ni de outros meios, como leitos contaminados. 


\subsection{Isotermas de adsorção}

Com o intuito de analisar o perfil de adsorção de Ni no catalisador remediado segundo o experimento 4 , foram feitos os ensaios de adsorção em banho finito e os resultados obtidos estão apresentados na figura 2.

A figura 2 que representa o gráfico que relaciona a concentração inicial de níquel (Co) no banho finito com a concentração deste metal no equilíbrio (Ce) após 30 minutos de adorção de $\mathrm{Ni}$ no catalisador remediado $(\mathrm{CR})$, catalisador novo $(\mathrm{CN})$ e catalisador desativado (CD).

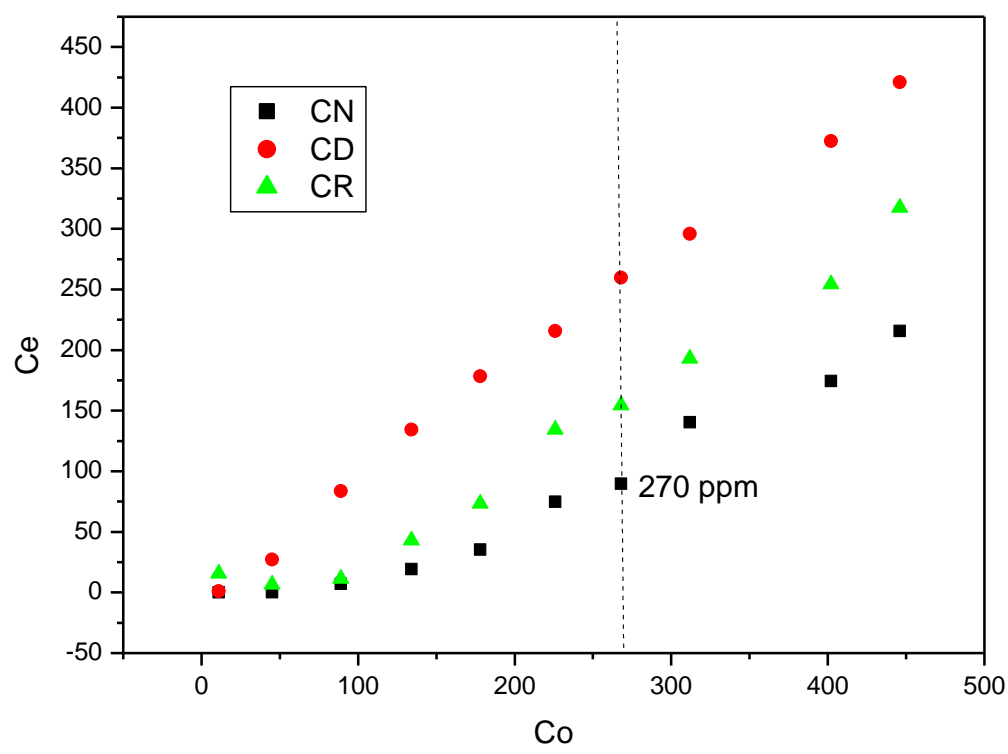

Figura 2 - Perfil de concentração de níquel no equilíbrio para diferentes concentrações iniciais.

Analisando a figura 2, foi possível observar que para uma mesma concentração inicial de $\mathrm{Ni}(270 \mathrm{ppm})$ a concentração de equilíbrio Ce determinadas para $\mathrm{CN}$ foi de 84,17 ppm, para CD 259,58ppm e para CR 154,24 ppm, mostrando que CN adsorve mais Ni que CR, e que CR adsorve mais Ni que CD. Sendo que CN apresentou uma porcentagem de adsorção de $68,82 \%$ e CR 42,87\%, enquanto CD 3,86\% como já era esperado por se tratar de um catalisador desativado, ou seja, um material que perdeu sua propriedade de adsorver espécies devido à obstrução dos seus poros por contaminantes do craqueamento do petróleo. Em relação ao catalisador desativado, CR apresentou uma capacidade 11 vezes maior de adsorção de $\mathrm{Ni}$, mostrando que o processo de remediação eletrocinética para catalisadores desativados foi eficiente.

A figura 3 mostra a representação da isoterma de adsorção de Freundlich para os três catalisadores. Onde pode-se observar que CD apresenta baixa capacidade de adsorção independente da concentração de equilíbrio. Já CR apresenta uma capacidade de adsorção de Ni muito maior que CD e que quanto maior a concentração de equilíbrio maior a quantidade de $\mathrm{Ni}$ adsorvida no catalisador, tendendo a uma saturação em torno de 200ppm. 


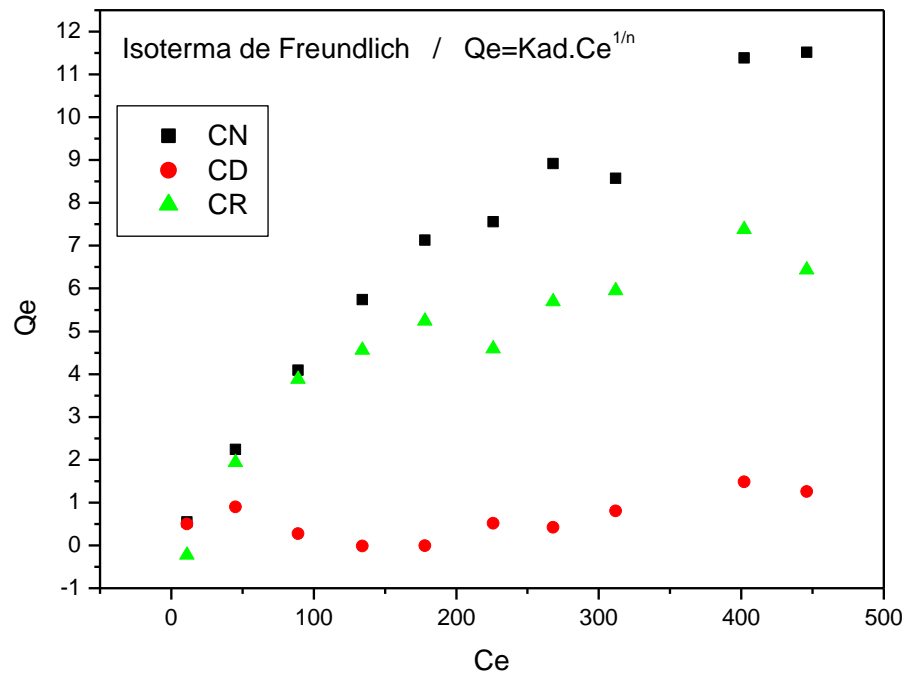

Figura 3 - Isoterma de adsorção de Freundlich para Ni em catalisador.

\section{CONCLUSÕES}

Ao término dos experimentos foi possível verificar que o catalisador remediado, mesmo não estando totalmente livre de contaminantes, consegue adsorver uma quantidade 11 vezes maior de níquel comparado ao desativado, sendo os valores próximos aos valores observados em um catalisador novo.

Da mesma forma que os resultados da remediação apontaram que os ensaios realizados na condição de $0,5 \mathrm{~mol} / \mathrm{L}$ de citrato de sódio e $11 \mathrm{~V}$ de tensão, forneceram os melhores índices de remoção de níquel e vanádio, a técnica de remediação eletrocinética foi eficiente para remover metais do catalisador desativado.

\section{REFERÊNCIAS BIBLIOGRÁFICAS}

ACAR, Y. B.; GALEB, R. J.; ALSHAWABKEH, A. N.; MARKS, R.E.; PUPPALA, W.; BRICKAD, M. and PARKERE, R. Electrokinetic remediation: Basics and technology status. Journal of Hazardous Materials v. 40, 117-137, 1995.

ALMEIDA, A. M.; et al. Relatório: Prática 1- 1 Bimestre - Isoterma de Adsorção. Faculdade de Telêmaco Borba, Telêmaco Borba, Paraná, 2009.

BAPTISTA, A. Avaliação do potencial de recuperação de metais de catalisadores equilibrados através da técnica de remediação eletrocinética.2005. 131f. Dissertação (Mestrado em Engenharia de Materiais e Processos)Universidade Federal do Paraná, Curitiba, Paraná, 2005.

CREPLIVE, M. R. Remoção de vanádio a partir de catalisadores termodinamicamente estáveis. Dissertação (Mestrado em Fenômenos de Transporte e Mecânica dos Sólidos) Universidade Federal do Paraná, Curitiba, Paraná, 2008 
PONTE,M.J.J.S. Estudo da Remoção do Íon Cobre de Solução Aquosa Diluída em Eletrodo de Leito Fluidizado (Tese de Doutotorado). Programa de Pós-Graduação em Engenharia Química. Universidade Federal de São Carlos.1998

SANCHES, L. S. ; MASCARO., L. H. . Electrodeposition of Ni-Mo Alloys from Sulfate-Citrate Acid Solution. Journal of the Brazilian Chemical Society, v. 14, p. 556563, 2003.

SOARES, J.L. Desenvolvimento de novos adsorventes e processos híbridos em reforma catalítica por vapor de água. (Tese de Doutorado). Programa de PósGraduação em Engenharia Química. Universidade Federal de Santa Catarina. 2003

RAJESHWAR, K.; IBANEZ, J. G.; SWAIN, G. M. Electrochemistry and the environment. Journal of applied electrochemistry. V. 24, n.11, p.1077-1091, 1994.

VALT, R.B.G. Regeneração eletrocinética, reciclagem e reuso de catalisadores desativados de fec na adsorção de dióxido de carbono e craqueamento de petróleo. (Tese de Doutotorado). Programa de Pós-Graduação em Engenharia. Universidade Federal do Paraná. 2012 